\title{
ANALISIS PERSEPSI, SIKAP DAN PERILAKU KONSUMEN TERHADAP PANCAKE DURIAN (STUDI KASUS : PANCAKE DURIAN PRODUKSI CELEBRITY PANCAKE)
}

\author{
Analysis Perception, Attitude, And Behavior Of Consumer To Durian \\ Pancake (Case Study : Durian Pancake Production Of Celebrity \\ Pancake)
}

\author{
Desyanti Marbun, Basuki Sigit Priyono, dan Melli Suryanti \\ Jurusan Sosial Ekonomi Pertanian Fakultas PertanianUniversitas Bengkulu \\ E-mail: desymarbunlumbanbatu@gmail.com
}

\begin{abstract}
The research was aimed to analyze the perception, attitude and behavior of consumer durian pancakes production Celebrity Pancake. Research method: study area is defined as purposive on the street S.Parman in the city of Bengkulu. Consumer respondents were taken by used accidental sampling. Intended for consumers who purchase the products of durian pancake at Celebrity Pancake. Methods of data analysis used Likert scale, analysis of descriptive, and Fishbein. The result showed, consumer perceptions to attribute durian pancakes had been different result, that is attribute taste, flavour, color, and sachet appear are in good category, while the price is at category less well, The consumer attitudes to durian pancakes which indicated trend to a positive attitude. The consumer behaviour to durian pancakes product indicated behaviors liking. Consumer considers all the important attributes of the durian pancakes product.
\end{abstract}

Keywords: Perception, Attitude, behaviours, Consumer

\section{PENDAHULUAN}

\section{Latar Belakang}

Buah merupakan komoditi pertanian yang mudah rusak, tidak dapat disimpan lama karena cepat busuk dan mudah diserang hama atau penyakit. Demikian pula halnya dengan buah durian akan cepat rusak bila tidak ditangani dengan baik. Mulai dari panen sampai tiba di tangan konsumen (Sobir, 2010).

Peluang bisnis durian sangat bagus, saat ini permintaan dan harga durian tergolong tinggi, karena memberikan keuntungan menggiurkan bagi siapa saja yang membudidayakan. Sehingga bertanam durian merupakan sebuah prospek usaha agribisnis yang bagus. Alam Indonesia kaya akan berbagai buah-buahan segar yang tidak hanya lezat, melainkan juga bergizi dan dapat diolah ke dalam 
berbagai variasi makanan sehingga tidak membosankan. Maraknya berbagai varian makanan baru yang kini mulai bermunculan meramaikan persaingan pasar.

Buah yang dinobatkan sebagai The King Of Fruit ini tidak hanya lezat jika dimakan langsung, tapi juga nikmat diolah menjadi jus, es krim, dan berbagai hidangan penutup. Rasa dan aroma daging durian membuat para pengusaha berinspirasi untuk mengolah produk makanan dari bahan baku durian tersebut yang sekarang di gemari banyak masyarakat, durian salah satunya. Indonesia termasuk penghasil durian paling lezat di dunia, bersaing dengan Thailand. Di Indonesia, durian dapat diolah ke dalam bermacam-macam jenis makanan yang nikmat dan menggiurkan. Makanan olahan tersebut adalah pancake durian. (Anonimous, 2011).

Dengan banyaknya produsen produk olahan durian (pancake durian) tersebut sudah pasti setiap produsen atau pelaku usaha ingin menjadi yang terbaik. Salah satu kunci keberhasilan pelaku usaha adalah memahami dengan jelas kebutuhan dan keinginan pelanggan. Dengan mengetahui hal itu maka pelaku usaha dapat menetapkan, menjalankan, serta mengendalikan strategi pemasaran dengan tepat (Nitisusastro, 2011).

Untuk mengetahui dan memahami apa yang dibutuhkan dan diinginkan konsumen, maka pelaku usaha harus senantiasa melakukan monitoring terhadap perkembangan lingkungan pasar yang senantiasa berubah setiap saat sejalan dengan perubahan tuntutan kebutuhan dan keinginan konsumen. Oleh karena itu, maka pelaku usaha perlu mempelajari dengan cermat tentang konsumen dan segala perilakunya (Nitisusastro, 2011). Oleh karena itu penelitian ini bertujuan untuk mengetahui persepsi, sikap, dan perilaku konsumen terhadap pancake durian produksi Celebrity Pancake.

\section{METODE PENELITIAN}

\section{Metode dan Lokasi Penelitian}

Penentuan lokasi penelitian dilakukan secara sengaja (purposive sampling) dilaksanakan di Celebrity Pancake Jl. S. Parman, kota Bengkulu, Celebrity Pancake adalah produsen pancake durian skala industri rumah tangga (home industry). Celebrity Pancake merupakan salah satu outlet makanan olahan durian yang mengolah durian bersifat franchisee di kota Bengkulu. Penentuan lokasi penelitian ditentukan berdasarkan pertimbangan yaitu, tersedianya pancake durian yang menjadi objek penelitian. 


\section{Populasi dan Sampel}

Karena populasi dalam penelitian ini tidak diketahui maka jumlah responden yang akan diambil menggunakan formula Virtucio dalam Ponan, (2005).

$$
n=\frac{\mathrm{Z}^{2}\{\mathrm{p}(1-\mathrm{p})\}}{\{\mathrm{MOE}\}^{2}}
$$

dimana $\mathrm{n}$ adalah ukuran sampel, $\mathrm{Z}$ adalah nilai tabel distribusi normal pada taraf kepercayaan (95\%) adalah 1,96, P adalah peluang $(0,5)$, dan MOE adalah Standar Error $(10 \%)$

Dengan rumus di atas, maka responden yang diambil pada penelitian ini sebanyak 96 responden. Teknik penarikan sampel dilakukan dengan menggunakan metode accidental sampling dilokasi penjualan pancake durian produksi Celebrity Pancake di Kota Bengkulu. Menurut Sugiyono (2004), metode accidental sampling adalah cara menentukan sampel secara kebetulan, siapa saja yang secara kebetulan bertemu dengan peneliti dapat dijadikan responden bila dipandang orang yang ditemui itu memenuhi kriteria sebagai responden, Kriteria tersebut adalah:

1. Responden yang dinilai dapat mengerti pertanyaan-pertanyaan yang ada pada kuesioner penelitian.

2. Responden pernah membeli dan mengkonsumsi pancake durian produksi Celebrity Pancake minimal 2 kali.

\section{Teknik Pengumpulan Data}

Data yang diperlukan dalam penelitian ini berupa data primer dan data sekunder. Data primer diperoleh melalui proses wawancara dengan menggunakan kuesioner yang telah dibuat terlebih dahulu. Sedangkan data sekunder diperoleh melalui literatur-literatur yang bersangkutan dengan penelitian ini dan juga dari instansi yang terkait dalam penelitian ini.

\section{Metode Analisis Data}

\section{Analisis Deskriptif}

Dalam pengukuran persepsi konsumen terhadap pancake durian digunakan analisis deskriptif kuantitatif. Dimana analisis deskriptif kuantitatif adalah suatu pendekatan penelitian yang dilakukan dengan cara pengolahan dan penyajian data dengan mempergunakan perhitungan statistika yang melibatkan angka-angka atau skor sehingga memungkinkan peneliti untuk mengambil keputusan secara obyektif (Anonim, 2011).

Teknik analisis deskriptif kuantitatf ini biasa digunakan untuk penelitian yang bersifat eksplorasi, misalnya ingin mengetahui persepsi konsumen terhadap pancake durian produksi Celebrity Pancake di Kota Bengkulu. Penyajian 
data dalam penelitian ini berbentuk tabel atau distribusi frekuensi, kemudian hasil penelitian akan masuk dalam kategori baik, kurang baik, tidak baik.dengan merinci biaya-biaya keseluruhan pada usaha perikanan tangkap.

\section{Analisis Fishbein}

Untuk mengetahui sikap dan perilaku konsumen menggunakan metode Fishbein, model ini digunakan untuk mengetahui sikap konsumen terhadap keseluruhan atribut produk yang meliputi rasa, aroma, tampilan, harga, warna, dan kemasan, dengan rumus:

$$
A_{0}=\sum_{i=1}^{n} b_{i} \times e_{i}
$$

dimana, $A_{0}$ adalah Sikap terhadap perilaku tertentu, $b i$ adalah Tingkat kepercayaan konsumen bahwa suatu obyek (pancake durian) tersebut memiliki atribut $i$, ei adalah Evaluasi kepentingan konsumen terhadap atribut produk pancake durian, dan $\mathrm{n}$ adalah Jumlah hasil (outcome), pada kombinasi bi dan $e i$ dihitung (Simamora, 2003).
a. Jika $A_{0}<0$, maka nilai sikap konsumen negatif,
b. Jika $A_{0}>0$, maka nilai sikap konsumen positif,
c. Jika $A_{0}=0$, maka nilai sikap konsumen tetap.
Sskala interval dihitung dengan rumus :

$$
\text { interval }=\frac{\mathrm{a}(\mathrm{m}-\mathrm{n})}{\mathrm{b}}
$$

dimana a adalah jumlah atribut, $m$ adalah skor tertinggi dari keyakinan dan evaluasi sikap, $\mathrm{n}$ adalah skor terendah dari keyakinan dan evaluasi sikap, dan $\mathrm{b}$ adalah jumlah skala penilaian yang ingin dibentuk.

Untuk mengetahui atau memperoleh konsistensi antara sikap dan perilaku maka digunakan model maksud perilaku Fishbein:

$$
B \approx B_{I}=W_{1}\left(A_{0}\right)+W_{2}(S N)
$$

dimana, B adalah Perilaku Konsumen, $\mathrm{B}_{\mathrm{I}}$ adalah Maksud Perilaku, $\mathrm{A}_{0}$ adalah Sikap konsumen terhadap produk pancake durian, SN adalah Norma Subjektif, dan $\mathrm{W}_{1}, \mathrm{~W}_{2}$ adalah Bobot yang akan ditentukan yang menggambarkan pengaruh relatif dari komponen.

Kriteria pengambilan keputusan adalah sebaga berikut:

a) Jika B $>0$ artinya perilaku konsumen loyal terhada produk pancake durian

b) Jika $B \leq 0$ artinya perilaku konsumen tidak loyal terhadap produk pancake durian. 
Untuk mengukur norma subjektif atau faktor kelompok referensi digunakan rumus dibawah ini :

$$
S N=\sum b_{i} \times m_{i}
$$

dimana $S N$ adalah Norma subjektif konsumen terhadap kelompok referensi, $b i$ adalah Keyakinan konsumen terhadap pendapat kelompok referensi jika berperilaku tertentu, dan mi adalah motivasi konsumen perilaku.

\section{HASIL DAN PEMBAHASAN}

\section{Karakteristik Responden}

Hasil penelitian menunjukkan bahwa karakteristik konsumen berdasarkan jenis kelamin, sebagian besar konsumen membeli pancake durian adalah perempuan $(59,4 \%)$ dan sebagian kecilnya adalah laki - laki $(40,6 \%)$. Hal ini menunjukkan bahwa kaum perempuan lebih suka atau cenderung membeli pancake durian di Celebrity Pancake kota Bengkulu. Konsumen perempuan akan sangat senang ketika berbelanja sesuatu yang sudah banyak dikenal kalangan masyarakat. Sedangkan Konsumen laki-laki kebanyakan hanya sekedar ikutikutan atau coba-coba membeli pancake durian di Celebrity Pancake. Berdasarkan umur dapat dilihat bahwa jumlah konsumen terbanyak berada pada kategori muda (16-25 tahun) yaitu 74,0 \%. Usia mempengaruhi seseorang dalam mengambil keputusan. Anak-anak mengambil keputusan dengan cepat, cenderung tidak terlalu banyak pertimbangan. Ketika membuat keputusan remaja sudah mulai mempertimbangkan desain, mode, dan lain-lain, mereka cenderung emosional. Keputusan pembelian yang dilakukan oleh orangtua cenderung rasional, banyak yang dipertimbangkan seperti harga, manfaat, dan lain-lain (Sangadji dan Sopiah, 2013).

Tingkat pendidikan menentukan seseorang dalam menerima pengetahuan dan informasi. Konsumen yang memiliki pendidikan yang baik akan responsive terhadap informasi yang dapat mempengaruhi dalam pemilihan suatu produk ataupun merek (Sumarwan,2002). Dari hasil penelitian dilapangan, persentase konsumen menurut pendidikan terakhir yang paling banyak membeli dan mengkonsumsi pancake durian Celebrity Pancake adalah yang pendidikan terakhirnya SLTA $(57,3 \%)$, sedangkan persentase yang paling kecil adalah Pasca Sarjana $(1,04 \%)$ kemudian disusul dengan pendidikan Diploma $(8,3 \%)$, dan selanjutnya persentase pendidikan terakhir Sarjana (33,3\%). Hal ini menunjukkan bahwa tingkat pendidikan formal responden yang mengkonsumsi dan membeli pancake durian adalah tingkat SLTA.

Dari enam jenis pekerjaan, hasil penelitian menunjukkan bahwa jenis pekerjaan yang persentasenya tinggi dalam membeli pancake durian adalah mahasiswa/i (53,13\%) sedangkan yang terendah adalah guru/dosen (3,13\%). Pekerjaan seseorang dapat mempengaruhi cara memperoleh dan pola konsumsi. 
Mahasiswa/i banyak dijumpai oleh peneliti karena sesuai dengan selera mereka dan gaya hidup mereka, sedangkan untuk jenis pekerjaan lainnya biasanya karena ingin mencoba dan ikut-ikutan mengkonsumsi dan membeli pancake durian.

Dari hasil penelitian menunjukkan bahwa karakteristik konsumen menurut jumlah penghasilan yang memiliki persentase tertinggi adalah berpenghasilan rendah dengan persentase $53,125 \%$, sedangkan yang persentasenya rendah adalah berpenghasilan tinggi $18,75 \%$. Konsumen yang paling banyak membeli dan mengkonsumsi pancake durian adalah konsumen yang berpenghasilan rendah karena kebanyakan konsumen yang membeli dan mengkonsumsi pancake durian adalah mahasiswa/pelajar.

Karena mahasiswa/pelajar cenderung ketika membeli sesuatu produk lebih sering mengutamakan kualitas produk meskipun terkadang harga dari suatu produk tersebut mahal, tetapi kualitas produk tersebut dapat memuaskan keinginan mereka.

Tabel 1 Persepsi Konsumen Terhadap Atribut Pancake Durian Produksi Celebrity Pancake Di Kota Bengkulu

\begin{tabular}{|c|c|c|c|c|c|}
\hline No & Atribut & Interval Skor & Kategori & Frekuesi & Persentase (\%) \\
\hline \multirow[t]{3}{*}{1} & \multirow{3}{*}{ Rasa } & $43-55$ & Sangat Manis & 77 & 80,21 \\
\hline & & $32-42$ & Manis & 14 & 14,58 \\
\hline & & $21-32$ & Kurang Manis & 5 & 5,21 \\
\hline \multirow{3}{*}{2} & \multirow{3}{*}{ Aroma } & $35-45$ & Sangat Harum & 73 & 76,04 \\
\hline & & $26-34$ & Harum & 19 & 19,79 \\
\hline & & $16-25$ & Kurang Harum & 4 & 4,17 \\
\hline \multirow{3}{*}{3} & \multirow{3}{*}{ Harga } & $9-11$ & Sangat Mahal & 26 & 27,08 \\
\hline & & $6-8$ & Mahal & 61 & 63,54 \\
\hline & & $4-6$ & Kurang Mahal & 9 & 9,38 \\
\hline \multirow{3}{*}{4} & \multirow{3}{*}{ Warna } & $8-10$ & Sangat Menarik & 73 & 76,04 \\
\hline & & $6-7$ & Menarik & 22 & 22,92 \\
\hline & & $4-5$ & Kurang menarik & 1 & 1,04 \\
\hline \multirow{3}{*}{5} & \multirow{3}{*}{$\begin{array}{l}\text { Tampilan } \\
\text { Keamasan }\end{array}$} & $21-25$ & Sangat Bagus & 56 & 58,33 \\
\hline & & $17-20$ & Bagus & 36 & 37,50 \\
\hline & & $13-16$ & Kurang Bagus & 4 & 4,17 \\
\hline
\end{tabular}

Sumber: Data Hasil Olahan (2015)

Persepsi konsumen pancake durian terhadap atribut terbagi atas tiga kategori. Pada dasarnya, persepsi adalah sebuah proses yang dilakukan dalam menilai serta menginterpretasikan yang terpilih. Hampir seluruh konsumen memiliki persepsi yang baik terhadap atribut rasa, aroma, warna dan tampilan kemasan. Hal ini dapat dilihat pada tabel 1 dan terbukti pada saat dilakukan wawancara, para konsumen tertarik akan rasa, aroma, warna dan tampilan kemasan pancake durian yang diproduksi oleh Celebrity Pancake, dikarenakan pancake durian yang diproduksi oleh Celebrity Pancake lebih enak dinikmati 
daripada pancake durian yang diproduksi oleh produsen lain, dimana rasa dari pancake durian tersebut dapat memenuhi kepuasan para konsumennya. Begitu juga aroma pancake durian yang ditawarkan oleh Celebrity Pancake dapat menambah keinginan konsumen membeli pancake durian tersebut, dan tampilan kemasan yang didesain oleh Celebrity Pancake membuat konsumen merasa nyaman ketika membawa pancake durian tersebut. Celebrity Pancake juga sudah terkenal dikalangan masyarakat khususnya dikalangan mahasiswa. Atribut-atribut yang termasuk dalam kualifikasi baik menunjukkan bahwa atribut tersebut diyakini konsumen sudah mampu memenuhi kriteria pancake durian yang sesuai dengan keinginan konsumen. Tetapi beda halnya dengan harga, hampir seluruh konsumen menyatakan bahwa harga pancake durian yang diproduksi Celebrity Pancake ada pada kategori kurang baik, dikarenakan pancake durian yang dijual oleh produsen Celebrity Pancake berbeda dengan harga yang dijual oleh produsen lain, dan harganya lebih dari $2 x$ lipat dari harga pancake durian pada umumnya.

Hasil penelitian ini sesuai dengan hasil penelitian Missy Juwita (2013) melakukan penelitian tentang Persepsi Konsumen terhadap Bauran Pemasaran Produk Roti Holland Bakery Boulevard di Kota Manado. Adapun hasil dari penelitiannya bahwa persepsi konsumen terhadap bauran pemasaran produk roti dilihat dari segi produk, tingkat indeks persepsi konsumen tertinggi berada pada indikator citarasa produk. Sedangkan persepsi konsumen terhadap bauran pemasaran produk roti dari segi harga, tingkat indeks persepsi konsumen tertinggi berada pada indikator kesesuaian antara harga dengan kualitas dari roti yang diperoleh.

\section{Sikap Konsumen Terhadap Pancake Durian}

Tabel 2 menyajikan hasil estimasi sikap konsumen terhadap atribut pancake durian yang diproduksi oleh Celebrity Pancake Di Kota Bengkulu.

\section{Tabel 2 Sikap Fiesbien}

\begin{tabular}{|c|c|c|c|c|}
\hline No & Atribut & Keyakinan $\left(b_{i}\right)$ & Evaluasi $\left(e_{i}\right)$ & Sikap (AB) \\
\hline 1 & Rasa & 1,44 & 1,73 & 2,5 \\
\hline 2 & Aroma & 1,40 & 1,73 & 2,4 \\
\hline 3 & Harga & 0,79 & 0,33 & 0,3 \\
\hline 4 & Warna & 1,39 & 1,46 & 2,0 \\
\hline 5 & Tampilan Kemasan & 1,39 & 1,52 & 2,1 \\
\hline
\end{tabular}

Sumber: Data Hasil Olahan (2015)

Tabel 2 menunjukkan bahwa sikap konsumen terhadap atribut pancake durian memiliki nilai yang bervariasi mulai dari nilai yang tertinggi hingga yang terendah. Sikap konsumen yang tergolong kualifikasi nilai tertinggi adalah atribut rasa. Hal ini menunjukan bahwa pancake durian mampu memenuhi selera atau cita rasa konsumen dari pancake durian, karena rasa dari pancake 
durian tersebut terbukti disukai oleh konsumen ketika membeli pancake durian tersebut. Sedangkan nilai terendah adalah atribut harga, dimana atribut harga belum mampu memenuhi standar keyakinan konsumen, dimana harga pancake durian masih belum mampu untuk membuat kebanyakan konsumen setuju dengan harga yang ditawarkan oleh Celebrity Pancake. Nilai sikap konsumen pada tiap atribut yang beragam menggambarkan adanya perbedaan keyakinan konsumen terhadap beberapa atribut dengan kondisi kenyataan di lapangan.

Hal ini sejalan dengan hasil penelitian Sumarwan (2007) yang berjudul Analisis Sikap Multiatribut Fishbein Terhadap Produk Biskuit Sandwich Coklat, bertujuan untuk mengetahui sikap konsumen terhadap dua merek produk biskuit coklat yang berbeda (OREO dan RODEO) di Kota Bogor. Hasil Penelitian yang diperoleh adalah responden menganggap penting semua atribut biskuit sandwich coklat. Adapun atribut biskuit sandwich coklat ini adalah kerenyahan, tekstur, rasa coklat, warna produk, kemasan, dank krim isi. Berdasarkan skor Fishbein, responden lebih menyukai produk merek OREO dibandingkan RODEO. Semua atribut OREO memiliki skor sikap yang lebih tinggi dari RODEO, yang berarti bahwa semua atribut OREO dianggap lebih unggul atau lebih disukai konsumen dibandingkan RODEO.

Pada kolom total $\mathrm{AB}$ dapat dilihat bahwa keseluruhan total antara atribut keyakinan dan evaluasi adalah 9,3. Berdasarkan tabel 3 nilai total konsumen terhadap pancake durian produksi Celebrity Pancake $(\mathrm{AB})=9,3>0$, hal ini menunjukkan bahwa konsumen pancake durian produksi Celebrity Pancake memiliki sikap yang positif terhadap atribut-atribut yang ada pada pancake durian produksi Celebrity Pancake. Hasil penelitian ini sependapat dengan penelitian Serafina Setia (2011) yang berjudul, Analisis Preferensi Konsumen Dalam Membeli Daging Ayam Ras di Pasar Tradisional Kabupaten Karanganyar, hasil penelitian yang diperoleh adalah sikap konsumen terhadap atribut daging ayam ras yang paling dipertimbangkan dalam keputusan pembelian daging ayam ras di pasar tradisional Kabupaten Karanganyar adalah warna daging ayam ras. Menyatakan nilai sikap total konsumen berada pada nilai positif atau setuju, artinya pandangan konsumen tentang atribut pada daging ayam ras adalah positif.

Untuk mengetahui sikap total konsumen ini berada pada skala penilaian yang mana, maka perlu dihitung berapa nilai maksimum dan minimum untuk sikap. 
Tabel 3 Skala penilaian pada Pancake Durian

\begin{tabular}{clcccccc}
\hline \multirow{2}{*}{ No } & \multirow{2}{*}{ Atribut } & \multicolumn{3}{c}{ Skore terendah } & \multicolumn{3}{c}{ Skore tertinggi } \\
\cline { 3 - 8 } & & bi & ei & biei & bi & ei & biei \\
\hline 1 & Rasa & 0,79 & 0,33 & 0,2607 & 1,44 & 1,73 & 2,4912 \\
2 & Aroma & 0,79 & 0,33 & 0,2607 & 1,44 & 1,73 & 2,4912 \\
3 & Harga & 0,79 & 0,33 & 0,2607 & 1,44 & 1,73 & 2,4912 \\
4 & Warna & 0,79 & 0,33 & 0,2607 & 1,44 & 1,73 & 2,4912 \\
5 & Tampilan Kemasan & 0,79 & 0,33 & 0,2607 & 1,44 & 1,73 & 2,4912 \\
\hline & Total & & & 1,3035 & & & 12,456 \\
\hline
\end{tabular}

Sumber: Data Hasil Olahan (2015)

Karena rentang posisi sangat baik (SB) dan sangat tidak baik (STB), maka rentang nilai sikap maksimum adalah 12,456 dan minimum 1,3035.

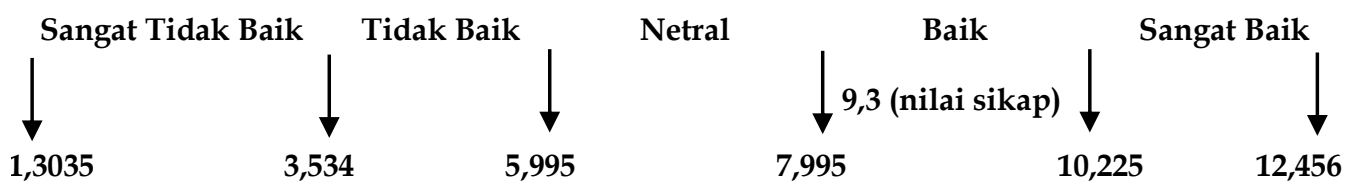

\section{Gambar 1}

\section{Skala Sikap Konsumen Terhadap Pancake Durina Produksi Celebrity}

Berdasarkan skala pada gambar 1, maka nilai sikap total konsumen terhadap pancake durian produksi Celebrity Pancake di Kota Bengkulu berada antara skala 7,995 dan skala 10,2255 yaitu 9,3 yang berarti nilai sikap total konsumen berada pada kategori baik. Secara keseluruhan konsumen setuju dengan atribut-atribut yang ada pada pancake durian produksi Celebrity Pancake. Hal ini dikarenakan sikap total konsumen $\left(\mathrm{A}_{\mathrm{B}}\right)>0$, yang menandakan bahwa sikap konsumen positif akan atribut-atribut yang ada produk pancake durian. Dan hampir semua atribut-atribut yang ada pada pancake durian mampu memenuhi keinginan konsumen dan konsumen menyukai pancake durian produksi Celebrity Pancake.

Penelitian ini sependapat dengan penelitian Afrizal (2003) yang berjudul, Analisis Sikap dan Perilaku Konsumen Terhadap Makanan Lempuk Yovita di Kota Bengkulu, yang menyatakan nilai sikap total konsumen berada pada nilai baik, yang mengidentifikasikan bahwa konsumen setuju dengan berbagai atribut yang ditawarkan Lempuk Yovita. 
Tabel 3 Nilai Norma Subjektif

\begin{tabular}{rlccc}
\hline No & \multicolumn{1}{c}{ Atribut } & Keyakinan Normatif & Motivasi & SN \\
\hline 1 & Keluarga & 0,53 & 0,95 & 0,50 \\
2 & Teman & 0,06 & $-0,44$ & $-0,03$ \\
3 & Promosi & 0,90 & $-0,21$ & $-0,19$ \\
\hline & Total SN & & & 0,29 \\
\hline
\end{tabular}

Sumber: Data Hasil Olahan (2015)

Dari Tabel 3 dilihat bahwa promosi $(0,9)$ lebih banyak memberikan saran dibandingkan teman $(0,06)$ dan keluarga $(0,53)$ untuk membeli pancake durian. Pada kolom motivasi dapat dilihat responden lebih mengikuti pendapat keluarga $(0,95)$, promosi $(-0,23)$, dan teman $(-0,44)$ Berdasarkan Tabel 3 jumlah nilai perilaku adalah 0,29 . Nilai perilaku yang paling tinggi adalah keluarga $(0,50)$. Jadi faktor eksternal konsumen lebih dipengaruhi oleh keluarga. Hal ini terlihat ketika melakukan wawancara, para konsumen menyatakan bahwa kebanyakan mereka mengenal pancake durian Celebrity Pancake tersebut karena promosi di jejaring sosial media, dikarenakan pemilik Celebrity Pancake sering mempromosikan pancake duriannya di jejaring sosial media. Selanjutnya keluarga yang mempengaruhi konsumen membeli pancake durian di Celebrity Pancake.

Nilai perhitungan perilaku konsumen yaitu hasil perkalian antara nilai sikap total $\left(\mathrm{A}_{\mathrm{B}}\right)$ dengan konstanta (w1) dan dijumlahkan dengan nilai total Norma Subjektif (SN) yang juga dikalikan dengan konstanta (w2). Dimana w1 = 0,7 dan $w 2=0,3$. Hasil nilai perilaku konsumen didapat sebagai berikut :

$$
\begin{aligned}
\mathrm{B} \approx \mathrm{BI} & =\mathrm{w} 1(\mathrm{AB})+\mathrm{w} 2(\mathrm{SN}) \\
& =0,7(9,3)+0,3(0,27) \\
& =6,51+0,081 \\
& =6,591
\end{aligned}
$$

Hasil nilai analisis perilaku konsumen menghasilkan nilai perilaku $(\mathrm{B})=$ 6,591 dimana nilai $B=6,591>0$ menunjukkan bahwa perilaku konsumen positif. Artinya, perilaku konsumen adalah baik atau loyal, dan akan membeli kembali produk pancake durian produksi Celebrity Pancake. Menurut Umar (1998), jika nilai B positif (lebih besar dari nol) maka tanggapan konsumen adalah baik. Ini mengidentifikasikan bahwa sikap konsumen $\left(A_{B}\right)$ yang hasilnya positif atau baik ada hubungan yang konsisten dengan perilaku konsumen (B) yang juga menghasilkan nilai positif atau baik. Hal ini sesuai dengan pendapat Nugroho (2003), bahwa sikap yang positif terhadap merek tertentu akan memungkinkan konsumen melakukan pembelian terhadap merek itu. Sebaliknya sikap negatif akan menghalangi konsumen untuk melakukan pembelian. Selanjutnya menurut Schiffman dan Kanuk (1997) dalam Afrizal (2002) juga berpendapat 
bahwa suatu ukuran sikap berpengaruh ekuivalen terhadap perilaku, jika tidak ada faktor lain yang diteliti.

Penelitian ini setara dengan hasil penelitian Frisdinawati dan Priyono (2012), yang menyatakan bahwa sikap mencerminkan perilaku. Tetapi hasil penelitian ini bertolak belakang dengan penelitian Betharia (2001), yang menyatakan tidak ada hubungan antara sikap dan perilaku konsumen terhadap makanan siap saji (fastfood) California fried chicken di Kota Bengkulu, artinya sikap yang positif tidak diikuti dengan perilaku yang positif juga dari konsumen.

\section{SIMPULAN DAN SARAN}

\section{Simpulan}

Berdasarkan hasil penelitian yang dilakukan tentang, "Analisis Persepsi, Sikap dan Perilaku Konsumen Terhadap Pancake Durian (Studi Kasus : Pancake Durian Produksi Celebrity Pancake), maka dapat diambil suatu kesimpulan sebagai berikut:

1. Persepsi konsumen terhadap atribut pancake durian memiliki hasil yang berbeda, dimana atribut rasa, aroma, warna, dan tampilan kemasan berada pada kategori baik, sedangkan atribut harga berada kategori kurang baik.

2. Berdasarkan hasil analisis fishbein, secara keseluruhan sikap total konsumen $\left(A_{B}\right)>0$ atau bernilai positif dengan nilai total sebesar $(9,3)$, yang berarti nilai sikap total konsumen berada pada nilai baik. Yang membuktikan bahwa sebagian besar konsumen setuju dengan berbagai atribut yang ada pada pancake durian. Dalam mengkonsumsi pancake durian atribut yang disukai responden adalah rasa dan aroma.

3. Perilaku konsumen dipengaruhi oleh dua faktor yaitu sikap total konsumen $\left(\mathrm{A}_{\mathrm{B}}\right)$ dan norma subjektif $(\mathrm{SN})$. Hasil yang diperoleh untuk perilaku konsumen terhadap pancake durian bernilai positif dengan nilai sebesar $(6,591)$ yang membuktikan bahwa sikap konsumen yang hasilnya positif atau baik, ada hubungan yang konsisten dengan perilaku konsumen yang juga menghasilkan nilai positif atau baik.

\section{Saran}

Produsen Celebrity Pancake perlu meningkatkan kualitas terhadap atributatribut yang ditawarkan pada pancake durian produksi Celebrity Pancake berdasarkan prioritas yaitu rasa, aroma, harga, warna dan tampilan kemasan. Meskipun hasil dari beberapa atribut bernilai positif, akan tetapi atribut harga memiliki nilai yang negatif, dimana konsumen masih menganggap harga dari pancake durian masih sangat mahal dan tidak terjangkau oleh semua kalangan masyarakat. Maka dari itu harus dilakukan evaluasi agar keinginan konsumen 
lebih terpenuhi dan memperoleh kualitas pancake durian yang baik. Seperti halnya atribut rasa, aroma, warna, tampilan kemasan, produsen harus lebih memperhatikan setiap kesukaan yang disukai para konsumen. Agar para konsumen semakin loyal membeli pancake durian tersebut. Begitu juga dengan promosi, produsen seharusnya lebih memplubikasi atau lebih mempromosikan pancake durian tersebut, baik di media sosial maupun menceritakannya melalui mulut ke mulut.

\section{DAFTAR PUSTAKA}

Anonimous, 2011. Bisnis Makanan Tradisional Semakin Diburu Pasar. Depok.

Betharia, 2001. Analisis Sikap dan Hubungannya dengan Perilaku Konsumen Makanana Siap Saji (Fast Food) California Fried Chicken di Kota Bengkulu. Skripsi. Jurusan Sosial Ekonomi Pertanian, Fakultas Pertanian, Universitas Bengkulu. (tidak diplubikasikan)

Frisdinawati D. dan Priyono Sigit Basuki. 2012. Analisis Sikap dan Perilaku Konsumen Terhadap Produk Donat Paket Surya Bakery di Kota Bengkulu. J. Agrisep 11(2): 197-203.

Juwita, Missy. 2013. Persepsi Konsumen terhadap Bauran Pemasaran Produk Roti Holland Bakery Boulevard di Kota Manado. Universitas Sam Ratulangi, Manado.

Nitisusastro, M. 2011. Perilaku Konsumen dalam Perspektif Kewirausahaan. Alfabeta. Bandung.

Nugroho J Setiadi, Konsep dan Implikasi untuk strategi dan penelitian pemasaran, Kencana, Jakarta, 2003.

Setia, Serafina. 2011. Analisis Preferensi Konsumen Dalam Membeli Daging Ayam Ras di Pasar Tradisional Kabupaten Karanganyar. Universitas Sebelas Maret. Surakarta

Simamora, Bilson. 2003. Membongkar Kotak Hitam Konsumen. Gramedia Pustaka Utama. Jakarta.

Sobir, Rodame M. Napitupulu, 2010. Bertanam Durian Unggul. Jakarta: Penebar Swadaya.

Sugiyono. 2004, Statistik Non Parametrik Untuk Penelitian. Edisi Revisi. CV ALFABETA. Bandung.

Sumarwan, 2007. Analisis Sikap Multiatribut Fishbein Terhadap Produk Biskuit Sandwich Coklat, yang berbeda (OREO dan RODEO) di Kota Bogor.

Sumarwan, U. 2002. Perilaku Konsumen, Teori dan Penerapannya Dalam Pemasaran. Penerbit Kerja Sama: PT. Ghalia Indonesia dengan MMA IPB. 